\title{
INTERVENTIONAL TREATMENT WITH PERIPHERAL NERVE BLOCKS CAN POSITIVELY INFLUENCE CHRONIC SCIATIC PAIN RESISTANT TO STANDARD ANALGESIC TREATMENT
}

\author{
Vrsajkov $\mathrm{V}^{1}$, Lukić-Šarkanović $\mathrm{M}^{1}$, Lazukic $\mathrm{A}^{1}$ \\ 1. Clinical Centre of Vojvodina, Novi Sad, Serbia
}

Objectives: Substantial increase in understanding of complex nature of neuropathic low back pain still not able to achieve satisfactory pain relief for more than $50 \%$ of patients on standard pharmacological therapy. The goal of our study was to evaluate therapeutic role of peripheral nerve blocks in reduction of pain in patients with chronic sciatic pain.

Methods: We obtained data from 48 patients treated between November 2013 and 2016. Every patient had insufficient reduction of pain after no less than 2 months of pharmacological treatment and significant problems with physical therapy. Patients received local anesthetic $(0.125 \%$ levobupivacaine) for every peripheral nerve block and corticosteroid (betamethasone) for last block. Pain was assessed by the use of numeric pain rating scale (NPRS), with range 0-10. Pain was evaluated before the application, 3-5 days after the first block and 4 weeks after the end of treatment.

Results: Our patients were $56.55 \pm 12.97$ year old. Chronic sciatic pain and failed back surgery syndrome were the main reasons for lower back pain. Peripheral neural block was made between 3 and 6 time with mean $3.28 \pm 1.04$ per patient. Mean pain score on NR scale before intervention was $8.32 \pm 1.40$. Wilcoxon signed rank test showed statistically significant differences between pain score before treatment and 3-5 days after the first block $(\mathrm{p}=0.000)$ and 4 weeks after the $\operatorname{last} \operatorname{block}(\mathrm{p}=0.000)$.

Discussion: As conclusion we can emphasize strong potential of peripheral nerve blockade in treatment of low back pain, especially for patients refractory to pharmacological therapy. 


\section{References:}

1. Baron R, Binder A, Attal N, Casale R, Dickenson AH, Treede RD. Neuropathic low back pain in clinical practice. Eur J Pain. 2016; 20(6):861-73

2. Datta S, Manchikanti L, Falco FJ, Calodney AK, Atluri S, Benyamin RM, Buenaventura RM, Cohen SP. Diagnostic utility of selective nerve root blocks in the diagnosis of lumbosacral radicular pain: systematic review and update of current evidence. Pain Physician 2013; 16(2):97124 